\title{
Prediksi, Optimalisasi Penggunaan Lahan, dan Nilai Tanah di Kota Bekasi
}

\author{
Rahmadya Trias Handayanto ${ }^{1,}$, , Haryono ${ }^{1}$, Sella Alayda Syifa ${ }^{1}$ \\ *Korespondensi:e-mail: rahmadya.trias@gmail.com
}

\begin{abstract}
Teknik Komputer; Universitas Islam 45 Bekasi; Jl. Cut Meutia No. 83 Bekasi, telp/fax (021) 8802015; e-mail: rahmadya.trias@gmail.com, h4ryon0.skom@gmail.com, shellaalas1716@gmail.com.
\end{abstract}

Submitted: 18 Maret 2021

Revised: 9 April 2021

Accepted: 30 April 2021

Published: 25 Mei 2021

\section{Abstract}

Urban planning management plays an importantrole in sustainable development because cities are the main source of environmental degradation. Limited land with high land prices makes it difficult to organize the city. There have been many studies discussing urban planning but most of them focus on one side, such as only prediction, optimization, orother aspects related to environment conservation. This study intends to discuss aspects of prediction, optimization and their relationship to land values in the city of Bekasi. Prediction results show the addition of buildings, especially in the city center. To optimize land use, especially in relation to high land prices in the city center, it is necessary to build vertical settlements.

Keywords: Land Change Modeler, Geographic Information Systems, Clustering, Driving Factors

\section{Abstrak}

Manajemen tata kota memegang peranan penting dalam pembangunan berkelanjutan karena kota merupakan sumber utama permasalahan lingkungan. Keterbatasa $n$ lahan dengan harga tanah yang tinggi menyebabkan sulitnya penataan kota. Riset yang membahas perencanaankota sudah banyak dilakukan, hanya saja kebanyakan focus kepada satu sisi, misalnya prediksi, optimalisasi, atau pun aspek-aspek lain yang terkait konservasi alam. Penelitian ini bermaksud membahas aspek-aspek prediksi, optimalisasi dan keterkaitannya dengan nilai tanah di kota Bekasi. Hasil prediksi menunjukan penambahan bangunan khususnya di pusat kota. Untuk mengoptimalkan penggunaan lahan, khususnya berkaitan dengan harga tanah yang tinggi $\mathrm{di}$ pusat kota, perlu dibangun pemukiman vertikal.

Kata kunci: Land Change Modeler, Sistem Informasi Geografis, Klasterisasi, Faktor Pendorong Perubahan Lahan 


\section{Pendahuluan}

Kota selalu dipersepsikan sebagai sumber utama kerusakan lingkungan karena region ini membutuhkan sumber daya alam yang besar seperti listrik, air, bahan bakar kendaraan, dan sebagainya (Burton et al., 1996; Steiner, 2008; Williams et al., 2000). Hal ini menjadi konsen Perserikatan Bangsa-Bangsa (PBB) yang merekomendasikan Tujuan Pembangunan Berkelanjutan (Sustainable Development Goals - SDGs) yang salah satu topiknya adalah perkotaan (UN, 2015).

Riset-riset terdahulu telah banyak membahas masalah perkotaan, seperti adanya eksklusivitas pada pemukiman di perkotaan (Firman, 2004). Hal ini kerap terjadi di pemukiman dengan harga tanah yang tinggi dan memerlukan tingkat keamanan untuk warganya. Selain itu, munculnya kota-kota kecil baru perlu penanganan khusus karena sedikit saja pemerintah daerah terlambat mengantisipasi, akibatnya akan terasa di masa depan (Mardiansjah, 2020). Kota Bekasi merupakan kota penting penyangga kota Jakarta dan masuk dalam kota metropolitan JABODETABEK, dengan fenomena post-urbanization dengan ciri khas pertumbuhan pesat di kota sekitar (Jakarta, Bogor, Depok, Tangerang, dan Bekasi) yang melebihi kota utama (DKI Jakarta) (Firman \& Fahmi, 2017).

Perkembangan Kota Bekasi sangat cepat mengingat kota ini menjadi penghubung DKI Jakarta dengan pusat industri di Cikarang, selain itu Bekasi juga merupakan daerah penyangga bagi lbu kota Jakarta (Herlawati \& Khasanah, 2020). Dengan dua gerbang tol, banyak pemukiman-pemukiman baru bermunculan di wilayah dengan karakteristik geologi yang baik dan tingkat kemiringan yang rendah sehingga sangat cocok untuk transportasi (Dirks et al., 1989).

Selain jalan raya, beberapa lokasi bisnis di Kota Bekasi menjadi pemicu bertambahnya penggunaan lahan. Beberapa industri di bagian utara dan selatan kota Bekasi membutuhkan dukungan infrastruktur seperti jalan utama, keamanan, dan pensuplai bahan bakar. Dengan tingkat perputaran ekonomi yang tinggi, kota ini menjadi lokasi pemukiman baik orang yang bekerja di pusat kota (DKI Jakarta), pusat industri (Cikarang), maupun di kota Bekasi itu sendiri sehingga populasinya pun meningkat dengan pertumbuhan sekitar 2 persen (Bureau of Statistics, 2015).

Dengan latar belakang tersebut di atas maka penelitian ini dilaksanakan. Penelitian ini menggunakan Sistem Informasi Geografis (SIG) sebagai dasar pengolahan data spasial. Klasterisasi digunakan untuk memetakan pusat-pusat pemukiman, industri, dan bisnis. Analisa juga melibatkan harga tanah di kota penyangga Jakarta ini.

\section{Metode Penelitian}

Penelitian ini menggunakan data citra satelit berbasis waktu (spatio-temporal) untuk memprediksi perubahan lahan. Beberapa faktor pengendali diambil dari ris et-ris et terdahulu seperti jarak dengan jalan, pemukiman, sungai, pusat kota, dan lain-lain (Handayanto et al., 
2018). Sebagai alat bantu, software IDRISI dan ArcGIS 10.1 digunakan dengan modul Land Change Modeler (LCM).

Klasterisasi juga banyak diterapkan untuk menentuka zona-zona tertentu seperti pusat perekonomian/bisnis, industri, pemukiman, dan lain-lain (Herlawati et al., 2020). Penelitian ini menggunakan Fuzzy C-Means Clustering yang ada di module find-cluster software Matlab 2008b untuk proses klasterisasi penggunaan lahan.

Diperlukan dua jenis peta tematik klasifikasi lahan kota Bekasi yaitu 2000, 2010, dan 2015. Peta tematik tersebut diolah dari citra satelit Land sat yang diklasifikasi menggunakan modul isoclust yang ada pada IDRISI Selva. Selain data spasial, diperlukan data harga tanah yang ada di kota Bekasi (Bureau of Statistics, 2015).

\section{Hasil dan Pembahasan}

Hasil penelitian ini terbagi menjadi tiga bagian yaitu prediksi, klasterisasi dan keterkaitan dengan nilai tanah.

\subsection{Prediksi Penggunaan Lahan}

Gambar 1 menunjukan hasil klasifikasi tutupan/penggunaan lahan di kota Bekasi. Proses yang dilakukan adalah: (a) Klasifikasi dengan Isoclustdi IDRISI Selva, (b) Klasifikasi ulang dengan fungsi Reclass dan, (c) Pemotongan Citra Satelit mengikut area penelitian.

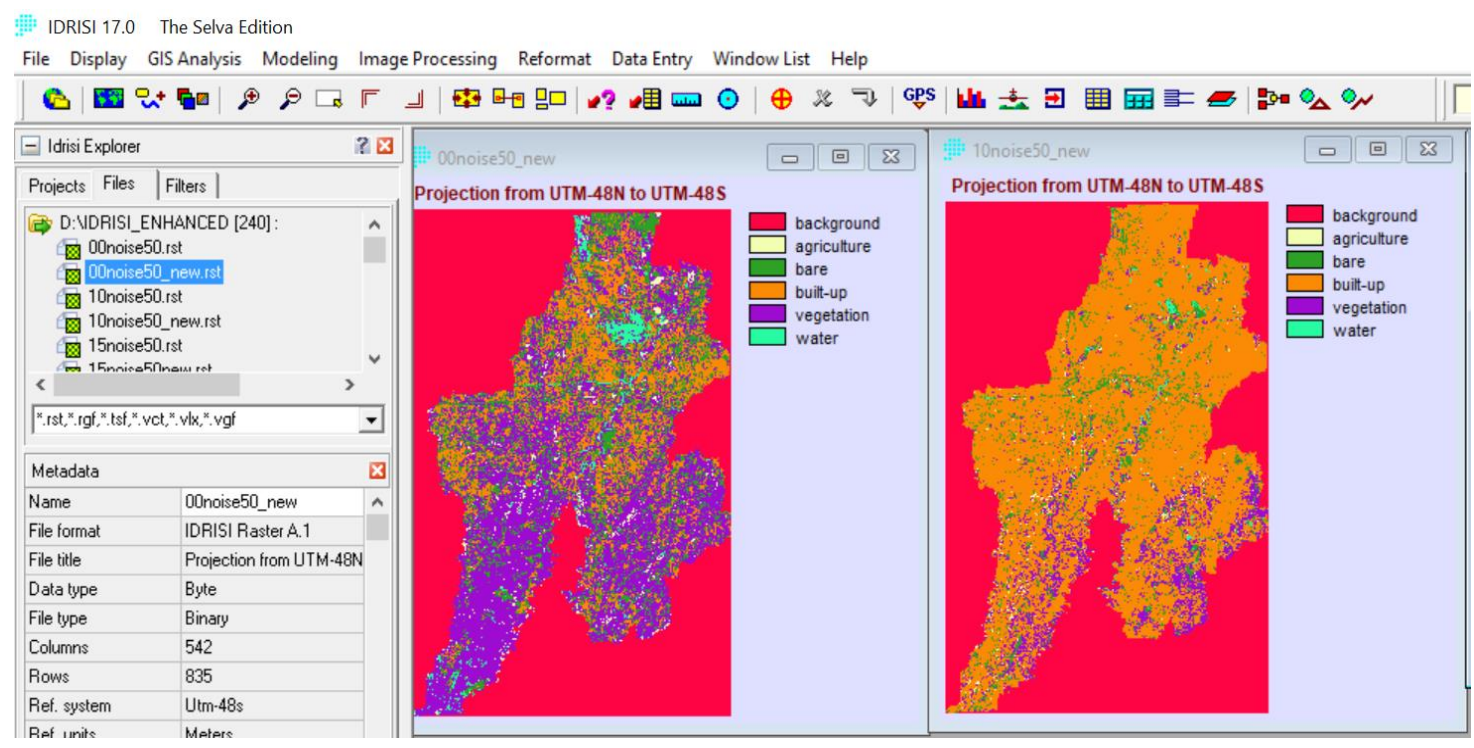

Sumber: Hasil Pengolahan Data (2021)

Gambar 1. Klasifikasi Lahan Tahun 2000 dan 2010 di Kota Bekasi

Hasil klasifikasi menunjukan perubahan vegetasi (berwarna ungu) menjadi bangunan (berwarna coklat), terutama di bagian selatan yang sebagian besar didominasi dengan pemukiman. Selanjutnya beberapa faktor pengendali perlu ditambahkan untuk memprediksi perubahan tutupan/penggunaan lahan (Gambar 2). 


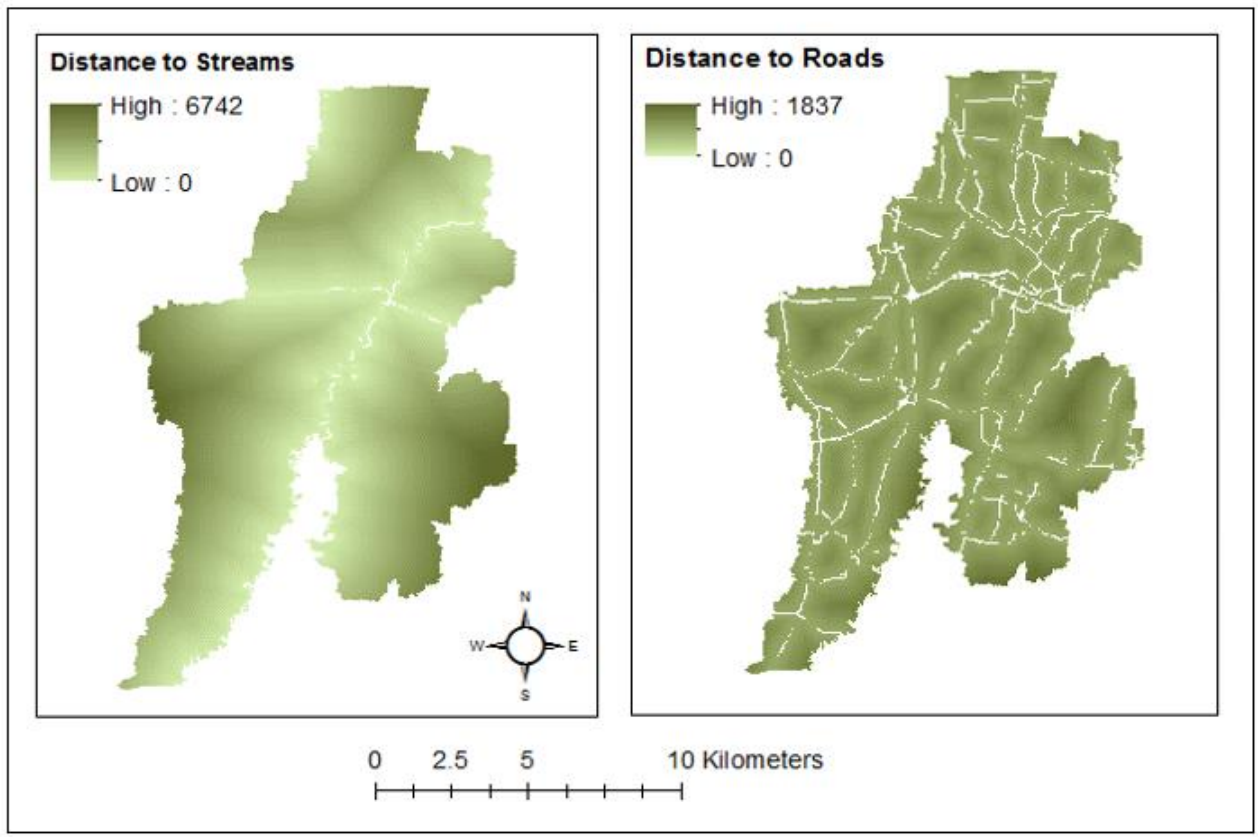

Sumber: Hasil Pengolahan Data (2021)

Gambar 2. Contoh Faktor Pengendali yang digunakan (jarak terhadap sungai dan jalan utama)

Modul LCM dibuat dengan menggunakan data spasial pada Gambar 1. Beberapa modifikasi perlu dilakukan karena kedua data spasial pada tahun yang berbeda harus memiliki kesamaan baik dari sisi template maupun ukuran agar bisa untuk prediksi. Gambar 3 menampilkan arah perubahan vegetasi menjadi bangunan yang berada di bagian tengah $\mathrm{d}$ an selatan.

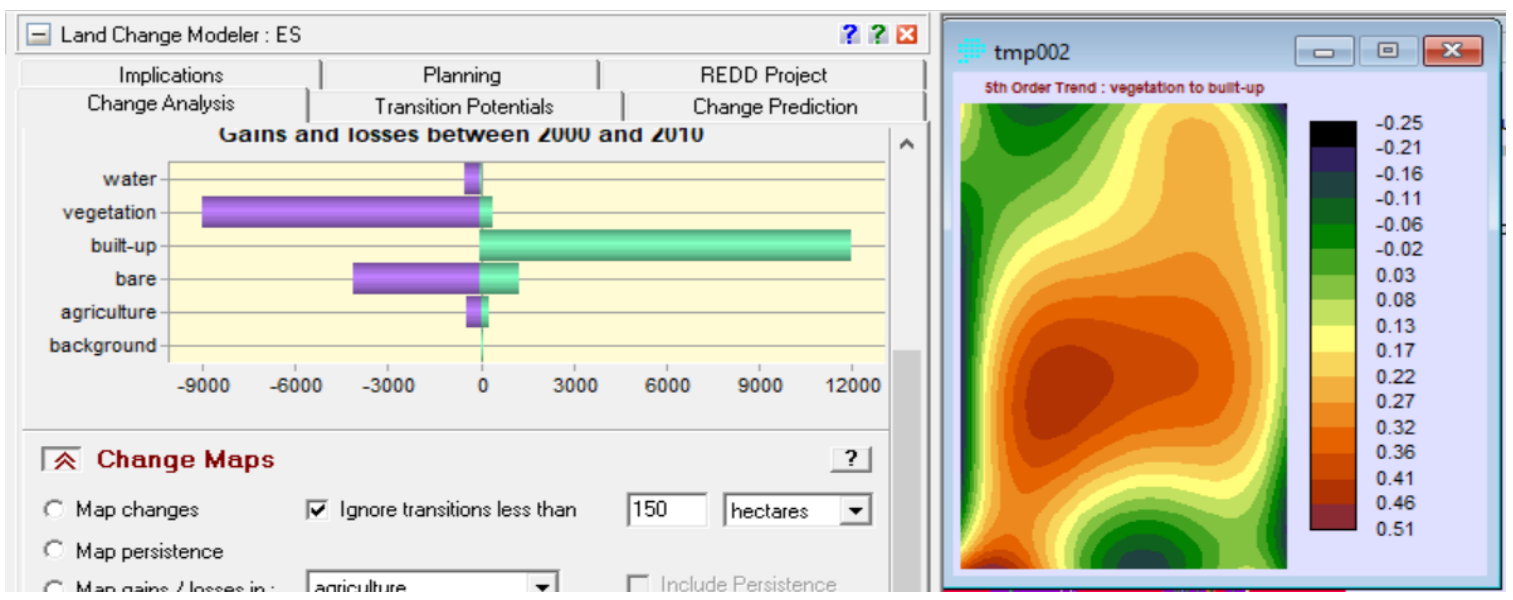

Sumber: Hasil Pengolahan Data (2021)

Gambar 3. Peta perubahan dari vegetasi ke Bangunan antara tahun 2000 dan 2010

Pada gambar 3 juga tampak ada perubahan dari lahan kosong (bare) menjadi bangunan, selain vegetasi. Selanjutnya dengan melakukan training menggunakan Multilayer Perceptron Neural Networks (MLPNN) yang ada di IDRISI diperoleh matrik transisi (Gambar 4). 


\begin{tabular}{|c|c|c|c|c|c|c|c|}
\hline \multicolumn{7}{|c|}{ - Land Change Modeler : ES } & ? ? 区 \\
\hline \multicolumn{3}{|c|}{ Implications } & \multicolumn{2}{|c|}{ Planning } & \multicolumn{3}{|c|}{ REDD Project } \\
\hline \multicolumn{3}{|c|}{ Change Analysis } & \multicolumn{2}{|c|}{ Transition Potentials } & \multicolumn{3}{|c|}{ Change Prediction } \\
\hline \multicolumn{5}{|c|}{$\sqrt{\widehat{\lambda}}$ Change Demand Modeling } & \multicolumn{3}{|c|}{$?$} \\
\hline \multirow{2}{*}{\multicolumn{2}{|c|}{$\begin{array}{l}\text { C Markov Chain } \\
\odot \text { External Model }\end{array}$}} & \multirow{2}{*}{\multicolumn{3}{|c|}{ Prediction Date : 2015}} & \multirow{2}{*}{\multicolumn{3}{|c|}{ View / edit matrix }} \\
\hline & & & & & & & \\
\hline \multicolumn{5}{|c|}{ 曹: Transition Probabilities Grid } & \multirow{2}{*}{\multicolumn{3}{|c|}{$x$}} \\
\hline \multirow[t]{2}{*}{ Given : } & \multicolumn{4}{|c|}{ Probability of changing to: } & & & \\
\hline & background & agriculture & bare & built-up & vegetation & water & \\
\hline background & 1.0000 & 0.0000 & 0.0000 & 0.0000 & 0.0000 & 0.0000 & \\
\hline agriculture & 0.0000 & 0.0998 & 0.2236 & 0.2130 & 0.4244 & 0.0392 & \\
\hline bare & 0.0000 & 0.0066 & 0.1908 & 0.7202 & 0.0777 & 0.0048 & \\
\hline built-up & 0.0000 & 0.0001 & 0.0001 & 0.9991 & 0.0003 & 0.0004 & \\
\hline vegetation & 0.0000 & 0.0321 & 0.1417 & 0.5328 & 0.2877 & 0.0058 & \\
\hline water & 0.0000 & 0.0215 & 0.4054 & 0.1941 & 0.1632 & 0.2159 & \\
\hline \multicolumn{4}{|c|}{ Save } & Clos & & & \\
\hline
\end{tabular}

Sumber: Hasil Pengolahan Data (2021)

Gambar 4. Matriks transisi dengan model Markov Chain

Matriks transisi tersebut digunakan untuk memprediksi perubahan tutupan/penggunaan lahan untuk kelas pertanian, lahan kosong, bangunan, vegetasi, dan perairan pada tahun 2015. Untuk validasi digunakan data real tahun 2015. Karena nilai Area Under the Curve of ROC (AUC) sudah memadai $(0,923)$ maka model dapat digunakan untuk memprediksi lahan ke depan.

Gambar 5 memperlihatkan hasil prediksi tutupan/penggunaan lahan di kota Bekasi untuk tahun 2030 dan 2050.

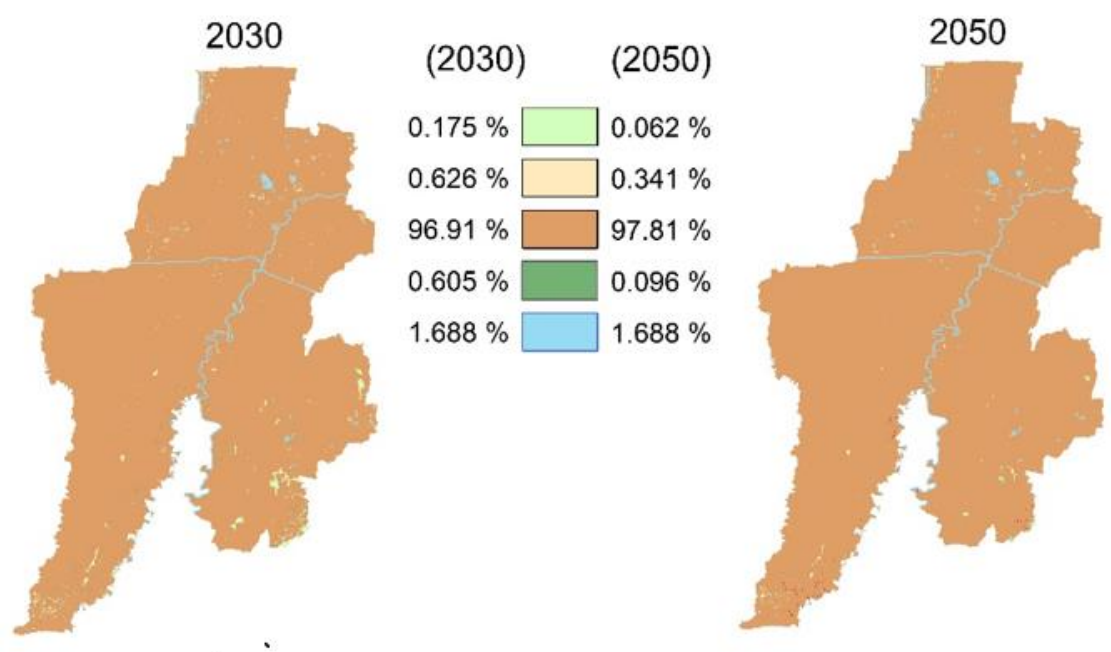

Sumber: Hasil Pengolahan Data (2021)

Gambar 5. Prediksi perubahan tutupan/penggunaan lahan tahun 2030 dan 2050 
Tanpa adanya kebijakan tertentu, misalnya menjaga perubahan vegetasi menjadi bangunan, maka pada tahun 2030 dan 2050 kota Bekasi hanya memiliki vegetasi sebesar berturut-turut 0,605\% dan 0,096\%, dibandingkan tahun 2015 yang sebesar 3,175\% (Tabel 1).

Tabel 1. Prosentase perubahan Penggunaan Lahan

\begin{tabular}{lrrr}
\hline Year & \multicolumn{1}{c}{$\mathbf{2 0 1 5}$} & $\mathbf{2 0 3 0}$ & $\mathbf{2 0 5 0}$ \\
\hline Pertanian & 453.62 & 36.79 & 13.051 \\
& $(2.155 \%)$ & $(0.175 \%)$ & $(0.062 \%)$ \\
Lahan Kosong & 568.89 & 131.73 & 71.823 \\
& $(2.703 \%)$ & $(0.626 \%)$ & $(0.34 \%)$ \\
Bangunan & 19075.88 & 20397.86 & 20588.631 \\
& $(90.626 \%)$ & $(96.907 \%)$ & $(97.813 \%)$ \\
Vegetasi & 668.22 & 127.27 & 20.146 \\
& $(3.175 \%)$ & $(0.605 \%)$ & $(0.096 \%)$ \\
Perairan & 282.39 & 355.35 & 355.349 \\
& $(1.342 \%)$ & $(1.688 \%)$ & $(1.688 \%)$ \\
\hline
\end{tabular}

Sumber: Hasil Penelitian (2021)

Selain vegetasi, pertanian juga mengalami penurunan dari 2,155\% di tahun 2015 menjadi 0,175\% dan 0,062\% di tahun 2030 dan 2050. Namun hal ini lumrah mengingat Bekasi telah bertransformasi menjadi kota yang memang tidak diperuntukan untuk pertanian seperti pada kabupaten Bekasi dan Karawang.

\subsection{Klasterisasi Penggunaan Lahan}

Klasterisasi menunjukan beberapa pusat klaster untuk pemukiman (Gambar 6a), industri (Gambar 6b), dan pusat bisnis (Gambar 6c).

(A)

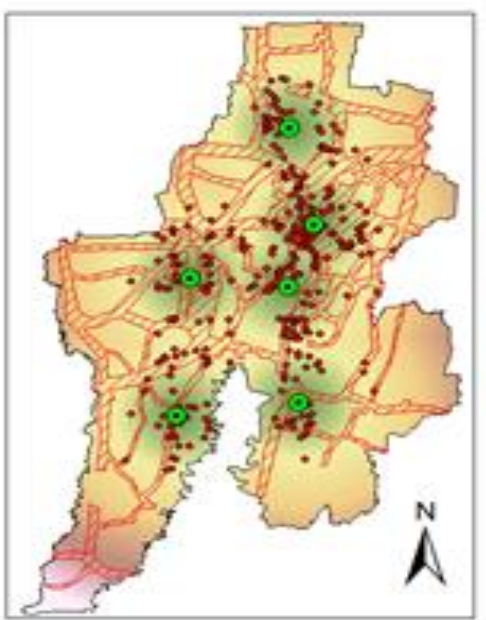

(B)

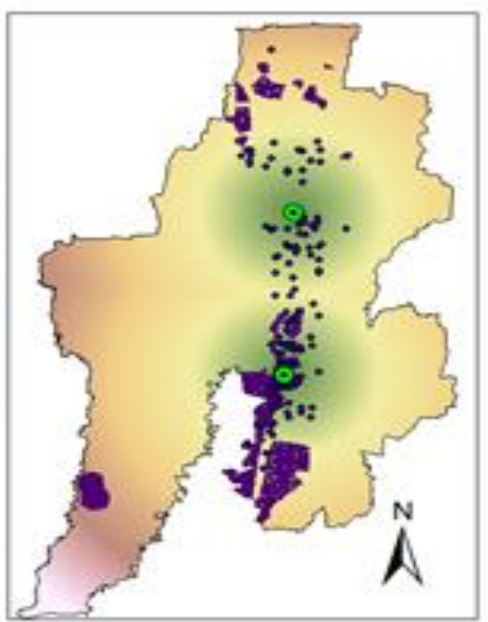

(c)

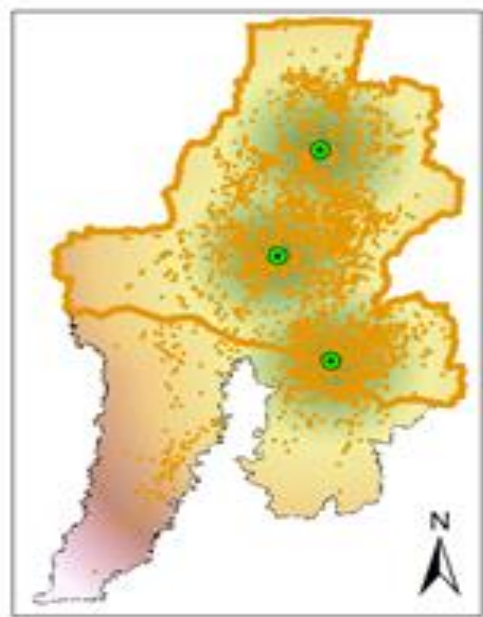

Sumber: Hasil Pengolahan Data (2021)

Gambar 6. Prediksi perubahan tutupan/penggunaan lahan tahun 2030 dan 2050

Pusat-pusat klaster pada gambar 6 dapat dijadikan rujukan dalam mengambil kebijakan tata ruang. Misalnya, pada gambar 6a pusat-pusat klaster dapat diperuntukan untuk pemukiman vertikal mengingat keterbatasan lahan yang ada. Pusat-pusat bisnis pada Gambar 6c perlu mendapat akses jalan yang baik, aman, bebas bencana (banjir, kebakaran, dan Iainlain). Untuk industri, kebanyakan sudah beralih menjadi industri ringan dan cenderung sebagai gudang/penyimpan. 


\subsection{Nilai Tanah}

Harga tanah sama halnya dengan harga-harga kebutuhan lain dimana akan tinggi ketika permintaan tinggi pula. Gambar 7 memperlihatkan hubungan harga tanah (per meter) dengan populasi. Walaupun harga tanah tidak bisa dipastikan dan cenderung berub ah tetapi relatif sama antara satu daerah dengan daerah lainnya.

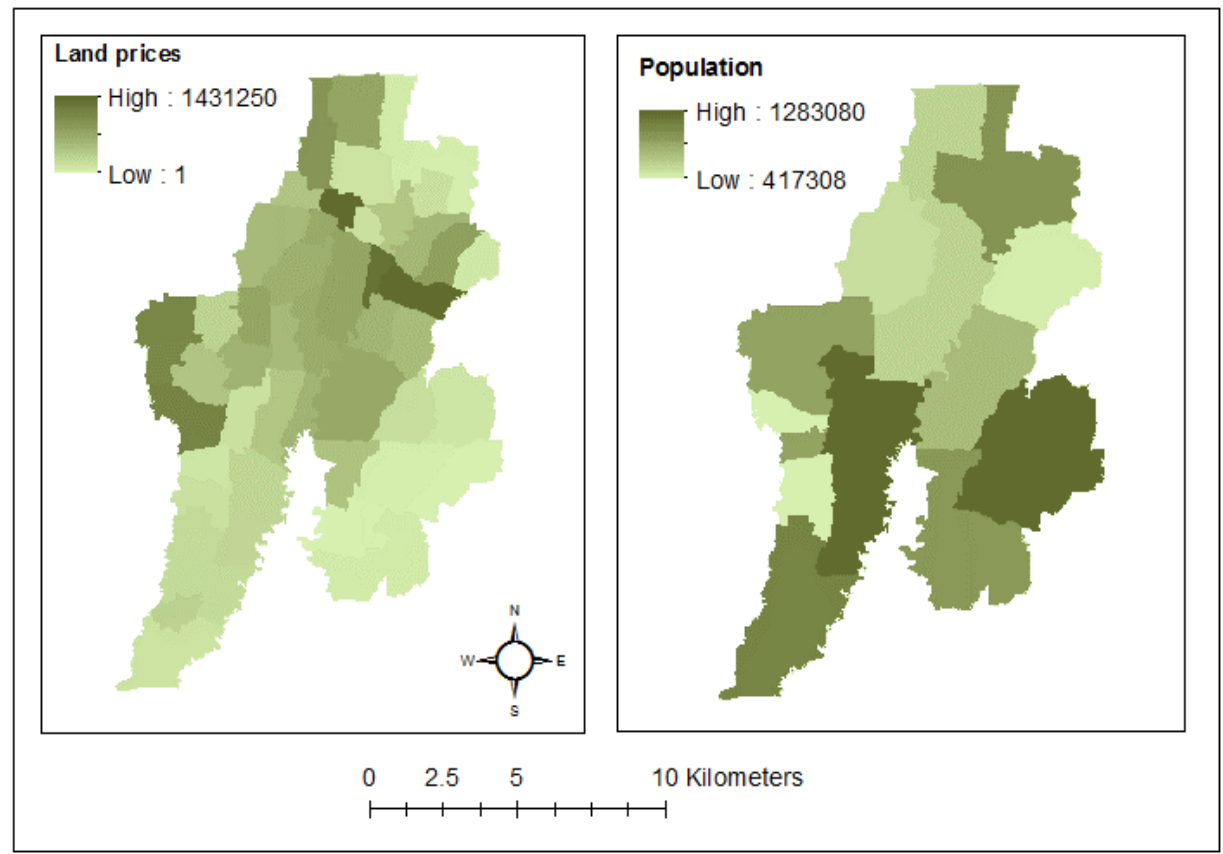

Sumber: Hasil Pengolahan Data (2021)

Gambar 7. Harga Tanah (Kiri) dan Populasi (Kanan)

Harga tanah yang tinggi ditunjukan dengan region yang gelap, begitu juga populasi yang tinggi. Harga tanah cenderung berada di lokasi pusat kota, atau yang berbatasan dengan ibukota, sementara populasi berkumpul di pusat bisnis, industry, dan pemukiman baru di wilayah selatan kota Bekasi. Secara administratif, tidak mungkin memisahkan secara tegas mengingat wilayah sekitar kota Bekasi dapat dipastikan terkena imbas baik nilai tanah maupun populasinya.

\section{Kesimpulan}

Untuk mengantisipasi tuntutan yang tinggi dari suatu kota maka perencana kota perlu memperhatikan kebutuhan-kebutuhan yang diperlukan penduduknya. Penelitian ini menunjukan perubahan kota Bekasi hingga tahun 2050 dimana pertumbuhan bangunan yang pesat. Dampaknya adalah berkurangnya vegetasi atau area hijau yang sangat diperlukan untuk pemenuhan oksigen. Perencana kota juga perlu menganalisa pusat-pusat klaster tertentu, seperti pusat bisnis, industry dan pemukiman guna menyediakan akses dan sarana dan prasarana yang sesuai dengan peruntukan lahannya. Hasil klasterisasi menunjukan bahwa harga tanah berkolerasi dengan pusat bisnis dan industry yang berada di pusat kota Bekasi. 


\section{Ucapan Terima Kasih}

Penelitian ini didanai oleh LPPM Universitas Islam “45” Bekasi. Peneliti mengucapkan terima kasih kepada segenap pihak yang membantu selesainya penelitian dan juga reviewer yang telah memberikan masukan berharga.

\section{Daftar Pustaka}

Bureau of Statistics. (2015). Population of Bekasi City.

Burton, E., Williams, K., \& Jenks, M. (1996). The compact city and urban sustainability: conflicts and complexities. In M. Jenks, E. Burton, \& K. Williams (Eds.), The compact city - a sustainable urban form? (1st ed., pp. 231-247). E \& FN Spon.

Dirks, F. J. H., Rismianto, D., \& De Wit, G. J. (1989). Groundwater in Bekasi District, West Java, Indonesia. Natuurwetenschappelijk Tijdschrift., 70(1/4), 47-55.

Firman, T. (2004). New town development in Jakarta Metropolitan Region : a perspective of spatial segregation. 28, 349-368. https://doi.org/10.1016/S0197-3975(03)00037-7

Firman, T., \& Fahmi, F. Z. (2017). The Privatization of Metropolitan Jakarta's (Jabodetabek) Urban Fringes: The Early Stages of "Post-Suburbanization" in Indonesia. Journal of the American Planning Association, 83(1), 68-79. https://doi.org/10.1080/01944363.2016.1249010

Handayanto, R., Tripathi, N. K., Kim, S. M., \& Herlawati, H. (2018). Land Use Growth Simulation and Optimization for Achieving a Sustainable Urban Form. TELKOMNIKA (Telecommunication Computing Electronics and Control), 16(5), 2063-2072. https://doi.org/10.12928/telkomnika.v16i5.9309

Herlawati, H., Abdurachman, E., Heryadi, Y., \& Soeparno, H. (2020). GIS-Based MCDM for Central Business Suitability in a Small City. 2020 5th International Conference on Informatics and Computing, ICIC 2020, Mcdm. https://doi.org/10.1109/ICIC50835.2020.9288586

Herlawati, \& Khasanah, F. N. (2020). Penentuan Lokasi Lahan dengan Sistem Pendukung Keputusan Kriteria Jamak Berbasis Sistem Informasi Geograf is. Jurnal Komtika (Komputasi Dan Informatika), 4(2), 42-50.

Mardiansjah, F. H. (2020). Extended urbanization in smaller-sized cities and small town development in Java: The case of the Tegal Region. IOP Conference Series: Earth and Environmental Science, 447(1). https://doi.org/10.1088/1755-1315/447/1/012030

Steiner, F. (2008). The living landscape - An Ecological Approach to Landscape Planning Second Edition. ISLAND PRESS.

UN. (2015). Habitat III Issue Papers - Public Space. United Nation Conference on Housing and Sustainable Urban Development.

Williams, K., Burton, E., \& Jenks, M. (2000). Achieving Sustainable Urban Form.pdf. E \& FN Spon. 